\title{
Gender, Professional and Non-Professional Work, and the Changing Pattern of Employment-Related Inequality in Poor Self-Rated Health, 1995-2006 in South Korea
}

\author{
Il-Ho Kim ${ }^{1,2}$, Young-Ho Khang ${ }^{3}$, Sung-Il Cho ${ }^{4}$, Heeran Chun ${ }^{5}$, Carles Muntaner ${ }^{1,6}$ \\ 'Bloomberg Faculty of Nursing, University of Toronto, Toronto, Canada; ${ }^{2}$ Social Aetiology of Mental Illness (SAMI) CIHR Training \\ Program, Social Equity and Health Research Center for Addition and Mental Health, Toronto, Canada; ${ }^{3}$ Department of Preventive \\ Medicine, University of Ulsan College of Medicine, Seoul, Korea; ${ }^{4}$ School of Public Health and Institute of Health and Environment, \\ Seoul National University, Seoul, Korea; ${ }^{5}$ Department of Public Administration, Ewha Womans University, Seoul, Korea; ${ }^{6}$ Dalla lana \\ School of Public Health, University of Toronto, Toronto, Canada
}

\begin{abstract}
Objectives: We examined gender differential changes in employment-related health inequalities according to occupational position (professional/nonprofessional) in South Korea during the last decade.

Methods: Data were taken from four rounds of Social Statistical Surveys of South Korea $(1995,1999,2003$, and 2006) from the Korean National Statistics Office. The total study population was 55435 male and 33913 female employees aged 25-64. Employment arrangements were divided into permanent, fixed-term, and daily employment.

Results: After stratification according to occupational position (professional/nonprofessional) and gender, different patterns in employment - related health inequalities were observed. In the professional group, the gaps in absolute and relative employment inequalities for poor self-rated health were more likely to widen following Korea's 1997 economic downturn. In the nonprofessional group, during the study period, graded patterns of employment-related health inequalities were continuously observed in both genders. Absolute health inequalities by employment status, however, decreased among men but increased among women. In addition, a remarkable increase in relative health inequalities was found among female temporary and daily employees $(p=0.009,<0.001$, respectively), but only among male daily employees $(p=0.001)$. Relative employment-related health inequalities had clearly widened for female daily workers between 2003 and $2006(p=0.047)$. The 1997 Korean economic downturn, in particular, seemingly stimulated a widening gap in employment health inequalities.

Conclusions: Our study revealed that whereas absolute health inequalities in relation to employment status increased in the professional group, relative employment-related health inequalities increased in the nonprofessional group, especially among women. In view of the high concentration of female nonstandard employees, further monitoring of inequality should consider gender specific patterns according to employee's occupational and employment status.
\end{abstract}

Key words: Gender, Employment status, Health inequality, Self-rated health

J Prev Med Public Health 2011;44(1):22-31

\section{INTRODUCTION}

Concerns have been growing around the issue of unstable employment's health-deteriorating effects. South Korean studies have obtained results similar to studies from the West: employment-related health inequality is prevalent, especially among women [1-4]. Some literature suggested that health disparity according to employment status may play a crucial role in producing socioeconomic inequalities in health. Yet the debate is still ongoing as to whether nonstandard work can cause health disparity, and whether unstable

(cc) This is an Open Access article distributed under the terms of the Creative Commons Attribution Non-Commercial License (http://creativecommons.org/licenses/by-nc/3.0/) which permits unrestricted non-commercial use, distribution, and reproduction in any medium, provided the original work is properly cited. employment status in accordance with social stratification can impact differently health inequalities $[5,6]$.

In a dynamic labor market, health inequalities are no longer restricted to low-skilled, nonstandard job holders since evidence shows that nonstandard professional employees are exposed to employment disparities and detrimental health consequences $[7,8]$. In most countries, nonstandard professional employees are more likely to have job insecurity and a lower salary than standard professional employees $[8,9]$. In addition, female professionals in nonstandard employment are reportedly

Corresponding author : II-Ho Kim, MD, PhD

455 Spadina Avenue, Suit 300, Toronto, Ontario, M5S 2G8, Canada

Tel : +01-416-535-8501, Fax: +01-416-979-6811, E-mail : itho_kim@camh.net

Received : 21 April 2010, Accepted : 9 December 2010 
more at risk of experiencing negative working environments than their male counterparts [10]. Amidst an increase in the number of nonstandard employees, a strikingly sizable number of female professionals are inclined to choose nonstandard work in order to keep a work-family balance [9]. In the US, nonstandard professional employees constituted almost a third (30.5\% women, $28 \%$ men) of the total professional workforce [9]. In the UK, approximately a third of professional women and a tenth of professional men appear to fall into nonstandard work arrangements [8]. What remains controversial is whether nonstandard employment (as a peripheral part of the labor market) is associated with detrimental effects on health, and whether unstable employment affects, in different ways, the health of workers in each social stratum $[5,6]$. Additionally, a meager amount of previous literature captured the trends in employment-related health inequalities according to social position, especially in the lens of professional workers.

Against the background of accumulated evidence that supports findings of health deterioration among nonstandard employees [6], some countries initiated welfare reforms in their labor markets, and these reforms have influenced the characteristics of nonstandard work. For instance, the Danish "flexicurity" approach was introduced into some European countries to deal with the issues of job insecurity that nonstandard employees faced in the labor market [11]. This new paradigm was considered to be a "golden triangle," made up of three parts: flexible labor markets, comprehensive welfare systems, and active policies, such as life-long job training for the transitional laborer [11]. In contrast to Denmark's approach, labor market reforms in the UK, Germany, and France were implemented that continuously escalated social risks. In Germany, for example, the Social-Democratic Party and Green Coalition between 2003 and 2005 placed more limits on the welfare system. More specifically, the government not only curtailed unemployment benefits, but also restricted job training for the unemployed, thereby forcing them to accept low-paying jobs without social security [12]. Due to these diverse and dynamic changes in the labor market, country by country, the impact of nonstandard work on health is more likely to differ in accordance with each study's setting.

South Korea has also experienced rapid changes in its labor-market structure, especially following the 1997 economic crisis. The proportion of nonstandard employees increased from 43 to 56 percent between 1996 and 2005, with a noticeable increase in highly educated women and young employees [13]. Facing requests to improve the working conditions of nonstandard employees, in 1998, the Korean Tripartite Commission (government, labor unions, and management) initiated the "Special Committee on Measures for Nonstandard Work" [14]. This organization has made efforts to improve the conditions of nonstandard employees [15]. Yet little research has been done to understand the effect of the 1997 Korean economic crisis on employment health. In addition, the health issues for nonstandard professional employees are less likely to be carefully considered because the conventional belief is that they enjoy a high quality of life with a high level of work autonomy and mastery [7]. Remarkably, little is known about how this ongoing Commission's policies will affect health inequalities' reduction according to employment status. Therefore, the first goal of this study is to investigate the association between self-rated health and employment status, after stratifying by gender and occupational position (professional vs. nonprofessional). The second goal is to examine the trends of employment health inequalities according to gender and occupational position in light of the 1997 financial crisis and recovery as well as the Korean government's efforts to improve employment environments.

\section{METHODS}

\section{Design and Study Population}

Data were gathered from the Social Statistics Survey (SSS) conducted by the Korean National Statistical Office. The SSS consisted of eleven sections: family, income and consumption, labor, education, health, housing and transportation, environment, welfare, culture and leisure, safety, and social participation. In the SSS, the health, family, social participation, and labor sections were surveyed every 3 or 4 years. A random sampling design was applied. About 24998 national districts (ED's) were selected from the Population and Housing Census survey districts. In accordance with the major administration regions, the country is divided into 25 strata: 7 large cities and 9 provinces (18 dongs, ups, and myons). Each selected ED is divided into the same number of segments and each segment contains, on average, 5 households. Approximately 30000 households out of 1629 ED's were selected. Face-to-face interview surveys were conducted nationally in 1995, 1999, 2003, and 2006. The overall response rate was very high (more than $95 \%$ in all surveys). The total survey population 
Table 1. Year- and gender-specific numbers of study subjects according to occupational position and types of employment: 89348 Korean men and women aged 25-64 from 1995, 1999, 2003, and 2006 Social Statistics Survey of Korea

$\mathrm{n}(\%)$

\begin{tabular}{|c|c|c|c|c|c|c|c|c|}
\hline \multirow{2}{*}{ Number } & \multicolumn{2}{|c|}{1995} & \multicolumn{2}{|c|}{1999} & \multicolumn{2}{|c|}{2003} & \multicolumn{2}{|c|}{2006} \\
\hline & Men & Women & Men & Women & Men & Women & Men & Women \\
\hline Age (y) & 16173 & 8134 & 12678 & 7443 & 13399 & 8916 & 13185 & 9420 \\
\hline $25-29$ & 3439 (21.3) & $1760(21.6)$ & 2339 (18.5) & $1531(20.6)$ & 1854 (13.8) & 1603 (18.0) & $1722(13.1)$ & 1675 (17.8) \\
\hline $30-39$ & $6224(38.5)$ & $2680(33.0)$ & 4783 (37.7) & 2414 (32.4) & 4962 (37.0) & 2828 (31.7) & 4534 (34.4) & $2868(30.5)$ \\
\hline $40-49$ & 3597 (22.2) & $2084(25.6)$ & 3327 (26.2) & 2060 (27.7) & 4081 (30.5) & 2833 (31.8) & 4146 (31.4) & 3041 (32.3) \\
\hline $50-59$ & 2392 (14.8) & 1263 (15.5) & 1811 (14.3) & 1078 (14.5) & 2038 (15.2) & 1275 (14.3) & $2288(17.4)$ & $1483(15.7)$ \\
\hline $60-64$ & 521 (3.2) & 347 (3.6) & 418 (3.3) & $360(4.8)$ & 464 (3.5) & 377 (4.2) & 495 (3.8) & 353 (3.8) \\
\hline \multicolumn{9}{|l|}{ Total } \\
\hline Permanent & $11530(71.3)$ & 3098 (91.9) & 8156 (64.3) & 2191 (29.4) & 8775 (65.5) & 3052 (34.2) & 8724 (66.2) & $3638(38.6)$ \\
\hline Temporary & 2507 (15.5) & 3276 (40.3) & 2658 (21.0) & $3350(45.0)$ & 2946 (22.0) & $4311(48.4)$ & 2890 (21.9) & $4299(45.6)$ \\
\hline Daily & 2136 (13.2) & 1760 (21.6) & $1864(14.7)$ & 1902 (25.6) & 1678 (12.5) & 1553 (17.4) & 1571 (11.9) & $1483(15.8)$ \\
\hline Professional & 1804 & 639 & 1344 & 503 & 1586 & 985 & 1663 & 1147 \\
\hline Permanent & 1750 (97.0) & $587(91.9)$ & 1274 (94.8) & 432 (85.9) & 1464 (92.3) & $730(74.1)$ & 1542 (92.7) & 905 (78.9) \\
\hline Temporary & $51(2.8)$ & $48(7.5)$ & $64(4.8)$ & $63(12.5)$ & $120(7.6)$ & 250 (25.4) & $120(7.2)$ & 239 (20.8) \\
\hline Daily & $3(0.2)$ & $4(0.6)$ & $6(0.4)$ & $8(1.6)$ & $2(0.1)$ & $5(0.5)$ & $1(0.1)$ & $3(0.3)$ \\
\hline Non-professional & 14369 & 7495 & 11334 & 6940 & 11813 & 7931 & 11522 & 8273 \\
\hline Permanent & $9780(68.1)$ & 2511 (33.5) & $6882(60.7)$ & 1759 (25.3) & 7311 (61.9) & 2322 (29.3) & 7182 (62.3) & $2733(33.0)$ \\
\hline Temporary & $2456(17.1)$ & 3228 (43.1) & 2594 (22.9) & 3287 (47.4) & 2826 (23.9) & 4061 (51.2) & $2770(24.0)$ & $4060(49.1)$ \\
\hline Daily & $2133(14.8)$ & 1756 (23.4) & $1858(16.4)$ & 1894 (27.3) & 1676 (14.2) & 1548 (19.5) & $1570(13.6)$ & $1480(17.9)$ \\
\hline
\end{tabular}

was 173 402: 98443 males and 74956 females (50 326 in 1995, 40309 in 1999, 41953 in 2003, and 40814 in 2006). From the total survey population, this study used data from paid employees aged 25-64 from 1995, 1999, 2003, and 2006. Adults younger than 25 were excluded since many of them had not yet completed their education and were not in the labor market. Adults 65 years or older were not included because most employees retire at this age. As a result, a total study sample of 89348 was gathered from four SSSs: 55435 male and 33913 female employees (24 307 in 1995, 20 121 in 1999, 22315 in 2003, and 22605 in 2006).

\section{Health Outcome Measure}

Poor self-rated health was used as a health outcome. Self-rated health was measured by the question: "How would you rate your health compared to others your age?" All responses used a five-point Likert scale ranging from "very good" to "very poor." The "poor" and "very poor" groups were combined to form a category called 'poor self-rated health,' and the "very good," "good," and "fair" groups were combined as a reference.

\section{Employment Status and Occupational Position Measure:}

Using the Korean National Statistics Office's definition of employment status [16], this study designated fulltime permanent employment as standard employment and temporary and daily employment as nonstandard employment. "Permanent employment" was defined as full-time permanent work of more than one year's duration. "Temporary employment" was defined as limited contractual work of less than one year. "Daily employment" included daily contractual work of a duration of one-month or less.

In this study, occupational position was determined by the type of one's occupation according to the South Korean standard, based on the International Labor Organization's occupational classifications [17]. Occupational positions were frequently divided into 5 classes: professional, managerial and technical, skilled non-manual, skilled manual, and unskilled manual employment. In this study, occupational position was categorized into professional and nonprofessional groups. The professional group consisted of legislators, senior managers, administrators, and professionals while the nonprofessional group was made up of technicians, paraprofessionals, and office, service, sales, skilled agricultural, forestry, and fisheries workers, crafts and related trades, plant and machine operators, assemblers, and unskilled laborers.

\section{Statistical Analysis}

Data for men and women were analyzed separately. We used both relative and absolute measures to examine health inequalities according to employment status. These measures were used to determine whether the magnitude of health inequality had decreased. Absolute 
inequality was calculated by using the prevalence difference in self-rated health between the permanent employment group and the temporary/daily employment group. Relative risk was measured by calculating prevalence ratios (rate for temporary and daily employment/rate for the permanent employment group). Age-standardized prevalence, an absolute measure of inequality for poor self-rated health, was computed with age adjustments for five-year age groups. Confidence intervals of age-standardized prevalence were estimated, assuming a Poisson distribution of the cases of poor selfreported health. This process was conducted using a direct method, with total samples from all four surveys being the reference population. Prevalence differences (PDs) and 95\% confidence intervals (95\%CIs) were computed to measure absolute inequalities. Prevalence ratios (PRs) were calculated to measure relative inequalities, which showed aspects of employment inequalities in poor self-rated health. Several studies suggested that when the prevalence of the study's outcome is higher than $10 \%$ and varies remarkably during the study period, the odds ratio (OR) is likely to become problematic; it may lead to a biased conclusion for measuring the relative risks of socioeconomic health inequality, especially when measuring a health inequality trend [18]. What is widely believed is that prevalence ratios, obtained from a log-binomial regression using the PROC-GENMOD, are robust and valid for estimating variance and confidence intervals [19]. Thus, a logbinomial regression was used to estimate the PRs of poor self-rated health according to employment status, after stratification by gender and occupational position. Time trends in PRs ( $p$-value) were calculated by including interaction terms of employment arrangements and the variables that identified the year of the data within the model. Additionally, in order to measure the extent of change in employment inequalities, $p$-values for differences in PRs between 1995, 1999, 2003, and 2006 were calculated. All analyses were performed with SAS version 9.2 (SAS Inc., Cary, NC, USA).

\section{RESULTS}

As shown in Table 1, the proportion of employees aged 25-29 continuously declined between 1995 and 2006 for both men (8.2\% decrease) and women (3.8\% decrease). Over $60 \%$ of the working population was between the ages of 30 and 49 . The proportion of temporary employees had significantly increased during the 1995-2003 period and decreased slightly in 2006. An increase in the proportion of temporary employment was more noticeable for women than men. In the professional positions, for example, the increase in temporary employment was $13.3 \%$ (7.5\% (1995) to $20.8 \%$ (2006)) for women and $4.4 \%$ (2.8\% (1995) to $7.2 \%$ (2006)) for men. Expectedly, only a small number of daily employees held professional jobs. In the nonprofessional positions, the increase in temporary employment was significant for both men $(6.9 \%$ increase, $17.1 \%$ (1995) to $24 \%$ (2006)) and women (6\% increase, $43.1 \%$ (1995) to $49.1 \%$ (2006)). Unlike the increasing trends in temporary employment, the proportion of daily employment has steadily decreased for both genders, except for a slight increase in 1999.

As seen in Table 2, a remarkable improvement in selfrated health was observed between 1995 and 2006, regardless of employment status, gender, and occupational positions. Over the last twelve years, in general, the absolute differences in the prevalence between permanent and temporary/daily employees appeared to have decreased.

After stratification according to occupational position and gender, absolute employment-related health inequalities showed different trends. In the professional group, the prevalence differences in poor self-rated health between permanent and temporary employees became steeper for women (6.0\% increase, $-2.3 \%$ (1995) to $3.7 \%$ (2006)) than for men (2.6\% increase, $2.3 \%$ (1995) to 4.9\% (2006)). An absolute health inequality, as measured by prevalence differences, was observed, especially in the professional female group during the study period. More interestingly, poor self-rated health's prevalence for the female permanent group in 1995 appeared to be greater than its prevalence for their male counterparts (11.6\% vs. $8.4 \%)$, but the trend was reversed in 2006 (3.8\% vs. $4.0 \%$ ).

In the nonprofessional group, female temporary and atypical employees continuously showed a greater prevalence of poor self-rated health than their male counterparts, especially female atypical employees (male/female atypical, $16.8 \%$ / 27.1\% (1995); $10.9 \%$ / 16.4\% (2006)), and the gradient in absolute employment health inequalities slightly increased for women (temporary, 1\%; daily, $1.6 \%$ increase). The absolute health inequalities, however, seemed to decrease slightly among men ($0.1 \%$ to $-2.6 \%$ ).

Table 3 presented PRs (relative measures) and $p$ values for PR differences between years. For the total working population, the relative health inequalities according to employment status have increased significantly in both temporary and daily employment. A 
Table 2. Age-standardized prevalence, $95 \%$ confidence interval $(95 \% \mathrm{Cl}$ ) and prevalence differences (PD) of poor self-rated health according to the type of employment: 89348 South Korean men and women aged 25-64 from 1995, 1999, 2003, and 2006 Social Statistics Survey

\begin{tabular}{|c|c|c|c|c|}
\hline & 1995 & 1999 & 2003 & 2006 \\
\hline \multicolumn{5}{|l|}{ Total population } \\
\hline Permanent & $12.2(11.7-12.7)$ & $9.0(8.3-9.6)$ & $7.0(6.5-7.5)$ & $5.5(5.1-6.0)$ \\
\hline Temporary & $20.4(19.2-21.6)$ & $17.0(15.9-18.1)$ & $13.1(12.3-14.0)$ & $10.2(9.5-10.9)$ \\
\hline Daily & $21.2(19.8-22.7)$ & $20.8(19.4-22.3)$ & $16.8(15.3-18.3)$ & $13.1(11.7-14.5)$ \\
\hline PD² (Permanent vs. Temporary) & $8.2(6.9-9.6)$ & $8.0(6.8-9.3)$ & $6.1(5.1-7.1)$ & $4.7(3.8-5.5)$ \\
\hline PD² (Permanent vs. Daily) & $9.0(7.5-10.6)$ & $11.8(10.3-13.5)$ & $9.8(8.2-11.4)$ & $7.6(6.2-9.1)$ \\
\hline \multicolumn{5}{|l|}{ Professional } \\
\hline \multicolumn{5}{|l|}{ Total } \\
\hline Permanent & $9.0(7.3-9.9)$ & $6.9(5.6-8.1)$ & $4.2(3.4-5.1)$ & $4.1(3.3-4.9)$ \\
\hline Temporary & $10.3(1.8-18.1)$ & $17.7(6.5-28.8)$ & $10.1(5.8-14.3)$ & $9.3(4.6-13.9)$ \\
\hline PD² (Permanent vs. Temporary) & $1.3(-7.9-6.7)$ & $10.8(-0.4-22.0)$ & $5.9(1.5-10.2)$ & $5.2(0.5-10.0)$ \\
\hline \multicolumn{5}{|l|}{ Men } \\
\hline Permanent & $8.4(7.4-9.3)$ & $6.0(4.7-7.3)$ & $3.5(2.5-4.5)$ & $4.0(3.1-5.0)$ \\
\hline Temporary & $10.7(1.0-21.6)$ & $11.6(0.7-23.8)$ & $11.4(3.9-18.9)$ & $8.9(1.8-16.1)$ \\
\hline PD² (Permanent vs. Temporary) & $2.3(-9.2-12.6)$ & $5.6(-6.7-17.9)$ & $7.9(0.4-15.4)$ & $4.9(-2.4-12.1)$ \\
\hline \multicolumn{5}{|l|}{ Women } \\
\hline Permanent & $11.6(8.8-14.4)$ & $9.3(6.5-12.4)$ & $5.7(4.0-7.4)$ & $3.8(2.5-5.1)$ \\
\hline Temporary & $9.3(1.3-17.4)$ & $19.6(5.6-30.3)$ & $7.5(3.9-11.0)$ & $7.5(3.3-11.6)$ \\
\hline PD² (Permanent vs. Temporary) & $-2.3(-10.8-.2)$ & $10.3(-4.1-24.4)$ & $1.8(-2.2-5.7)$ & $3.7(0.6-7.4)$ \\
\hline \multicolumn{5}{|l|}{ Non-professional } \\
\hline \multicolumn{5}{|l|}{ Total } \\
\hline Permanent & $12.8(12.2-13.5)$ & $9.6(8.9-10.3)$ & $7.8(7.2-8.4)$ & $5.9(5.4-6.4)$ \\
\hline Temporary & $20.5(19.3-21.7)$ & $17.1(16.0-18.2)$ & $13.2(12.4-14.1)$ & $10.3(9.5-11.0)$ \\
\hline Daily & $21.3(19.9-22.7)$ & $20.8(19.3-22.2)$ & $16.8(15.3-18.3)$ & $13.2(11.8-14.6)$ \\
\hline PD² (Permanent vs. Temporary) & $7.7(6.2-9.0)$ & $7.5(6.2$ - 8.8) & $5.4(4.4-6.5)$ & $4.4(3.5-5.3)$ \\
\hline PD² (Permanent vs. Daily) & $8.5(6.9-10.1)$ & $11.2(9.5-12.8)$ & $9.0(7.4-10.6)$ & $7.3(5.8-8.8)$ \\
\hline \multicolumn{5}{|l|}{ Men } \\
\hline Permanent & $11.0(10.3-11.7)$ & $8.0(7.4-8.9)$ & $6.6(5.9-7.2)$ & $5.2(4.7-5.7)$ \\
\hline Temporary & $16.8(14.9-18.6)$ & $12.1(10.6-13.6)$ & $9.9(8.7-11.1)$ & $8.4(7.3-9.5)$ \\
\hline Daily & $16.8(15.0-18.5)$ & $15.8(14.0-17.6)$ & $14.5(12.5-16.5)$ & $10.9(9.1-12.6)$ \\
\hline $\mathrm{PD}^{2}$ (Permanent vs. Temporary) & $5.8(3.8-7.7)$ & $4.1(2.3-5.6)$ & $3.3(2.0-4.7)$ & $3.2(2.0-4.4)$ \\
\hline PD² (Permanent vs. Daily) & $5.8(3.9-7.6)$ & $7.8(5.7$ - 9.6) & $7.9(5.8-10.0)$ & $5.7(3.8-7.5)$ \\
\hline \multicolumn{5}{|l|}{ Women } \\
\hline Permanent & $20.2(18.2-22.2)$ & $16.6(14.2-19.0)$ & $12.0(10.2-13.7)$ & $7.9(6.5-9.2)$ \\
\hline Temporary & $23.3(21.6-24.9)$ & $20.8(19.2-22.4)$ & $16.0(14.7-17.2)$ & $12.0(10.9-13.0)$ \\
\hline Daily & $27.1(24.7-29.6)$ & $26.4(24.0-28.8)$ & $20.3(17.8-22.9)$ & $16.4(14.0-18.8)$ \\
\hline PD² (Permanent vs. Temporary) & $3.1(0.4-5.7)$ & $4.2(1.3-7.1)$ & $4.0(1.8-6.2)$ & $4.1(2.4-5.8)$ \\
\hline PD² (Permanent vs. Daily) & $6.9(3.7-10.1)$ & $9.8(6.4-13.2)$ & $8.3(5.3-11.5)$ & $8.5(5.7-11.3)$ \\
\hline
\end{tabular}

${ }^{1}$ Age adjusted prevalence of poor self-rated health were calculated with age adjustment to 5 year age groups according to the direct method with samples from all four Social Statistics Surveys being referent.

${ }^{2} \mathrm{PD}$ and $95 \% \mathrm{Cl}$ were calculated to measure absolute inequalities.

steep increase, in particular, was observed between 1995 and 1999 (temporary, $p=0.026$; daily, $p<0.0001$ ).

After stratification by occupation, significant health inequalities according to employment status were observed in both professional (except in 1995) and nonprofessional groups during the study period. After further stratification by gender, gender-specific patterns were observed. In the professional strata, statistically significant associations between employment status and poor self-rated health were found among male employees in 2003 (PR, 3.02; 95\% CI, 1.62 to 5.63) and among female employees in 2006 (PR, 1.82; 95\% CI, 1.01 to 3.31$)$. In the nonprofessional strata, graded patterns of employment health inequalities were observed in both genders during the study period.

Based on $p$ values for PR differences during the study period, significantly increasing trends in health inequalities were observed in the nonprofessional group (temporary, $p=0.027$; daily, $p<0.0001$ ). The magnitude of relative health inequalities has significantly increased in both female temporary and daily employees $(p<$ $0.009 ;<0.0001$, respectively), but the trend was observed only among male daily employees $(p=0.001)$. The increase of PRs between 1995 and 1999, in particular, was remarkable for nonprofessional employees of both genders. 
Table 3. Prevalence ratio (PR) and $95 \%$ confidence intervals $(95 \% \mathrm{Cl})$ of poor self-rated health according to the type of employment: 89348 Korean men and women aged 25-64 from 1995, 1999, 2003, and 2006 Social Statistics Survey of Korea

\begin{tabular}{|c|c|c|c|c|c|}
\hline & 1995 & 1999 & 2003 & 2006 & $p$ for trend \\
\hline \multicolumn{6}{|l|}{ Total population } \\
\hline PR $(95 \% \mathrm{Cl})$ of temporary vs. permanent & $1.62(1.51-1.73)$ & $1.83(1.68-1.99)$ & $1.84(1.68-2.01)$ & $1.86(1.68-2.05)$ & 0.008 \\
\hline PR difference ( $p$ value) & \multicolumn{4}{|c|}{$\llcorner p=0.026$} & \\
\hline PR $(95 \% \mathrm{Cl})$ of daily vs. permanent & $1.77(1.64-1.90)$ & $2.29(2.10-2.50)$ & $2.34(1.13-2.58)$ & $2.36(2.12-2.64)$ & $<0.001$ \\
\hline PR difference ( $p$ value) & \multicolumn{4}{|c|}{$[p<0.0001]$} & \\
\hline \multicolumn{6}{|l|}{ Professional } \\
\hline \multicolumn{6}{|l|}{ Total } \\
\hline $\mathrm{PR}(95 \% \mathrm{Cl})^{+}$of temporary vs. permanent & $1.34(0.80-2.32)$ & $1.99(1.23-3.22)$ & $2.16(1.43-3.25)$ & $1.87(1.19-2.96)$ & 0.36 \\
\hline PR difference ( $p$ value) & \multicolumn{4}{|c|}{$\left\llcorner p=0.301 \_\quad\left\llcorner p=0.799 \_\quad\llcorner p=0.653 \sqcup\right.\right.$} & \\
\hline \multicolumn{6}{|l|}{ Men } \\
\hline $\mathrm{PR}(95 \% \mathrm{Cl})^{+}$of temporary vs. permanent & $1.41(0.65-3.07)$ & $1.93(0.93-3.99)$ & $3.02(1.62-5.63)$ & $1.69(0.80-3.61)$ & 0.53 \\
\hline PR difference ( $p$ value) & \multicolumn{4}{|c|}{ 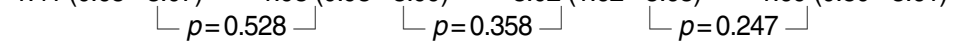 } & \\
\hline \multicolumn{6}{|l|}{ Women } \\
\hline $\mathrm{PR}(95 \% \mathrm{Cl})^{+}$of temporary vs. permanent & $0.97(0.56-2.42)$ & $1.62(0.85-3.09)$ & $1.41(0.83-2.39)$ & $1.82(1.01-3.31)$ & 0.43 \\
\hline PR difference ( $p$ value) & \multicolumn{4}{|c|}{$\left.\left.L_{p=0.505}\right\lrcorner \quad L_{p=0.741\lrcorner} L_{p=0.524}\right\lrcorner$} & \\
\hline \multicolumn{6}{|l|}{ Non-professional } \\
\hline \multicolumn{6}{|l|}{ Total } \\
\hline $\mathrm{PR}(95 \% \mathrm{Cl})^{+}$of temporary vs. permanent & $1.53(1.43-1.64)$ & $1.73(1.59-1.90)$ & $1.68(1.53-1.85)$ & $1.75(1.58-1.94)$ & 0.03 \\
\hline PR difference ( $p$ value) & \multicolumn{4}{|c|}{$\llcorner p=0.033$} & \\
\hline PR $(95 \% \mathrm{Cl})^{+}$of daily vs. permanent & $1.66(1.5-1.8)$ & $2.15(1.96-2.35)$ & $2.11(1.91-2.34)$ & $2.20(1.97-2.47)$ & $<0.001$ \\
\hline PR difference ( $p$ value) & \multicolumn{4}{|c|}{$\llcorner p=<0.0001 」 \quad\llcorner p=0.833\rfloor$} & \\
\hline \multicolumn{6}{|l|}{ Men } \\
\hline $\mathrm{PR}(95 \% \mathrm{Cl})^{+}$of temporary vs. permanent & $1.39(1.25-1.55)$ & $1.40(1.22-1.60)$ & $1.47(1.27-1.69)$ & $1.57(1.34-1.83)$ & 0.19 \\
\hline PR difference ( $p$ value) & \multicolumn{4}{|c|}{$\left.L_{p=0.953 \_} \perp p=0.640 \_\quad L_{p=0.537}\right\rfloor$} & \\
\hline PR $(95 \% \mathrm{Cl})^{+}$of daily vs. permanent & $1.57(1.4-1.74)$ & $1.98(1.74-2.25)$ & $2.15(1.87-2.48)$ & $1.99(1.69-2.34)$ & 0.001 \\
\hline PR difference ( $p$ value) & \multicolumn{4}{|c|}{ 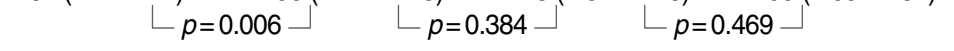 } & \\
\hline \multicolumn{6}{|l|}{ Women } \\
\hline PR $(95 \% \mathrm{Cl})^{+}$of temporary vs. permanent & $1.16(1.05-1.29)$ & $1.36(1.18-1.56)$ & $1.30(1.13-1.50)$ & $1.51(1.28-1.78)$ & 0.009 \\
\hline PR difference ( $p$ value) & \multicolumn{4}{|c|}{$\left\llcorner p=0.079 \_\quad\left\llcorner p=0.696 \_\quad\llcorner p=0.177\rfloor^{\prime}\right.\right.$} & \\
\hline PR $(95 \% \mathrm{Cl})^{+}$of daily vs. permanent & $1.33(1.19-1.49)$ & $1.63(1.41-1.89)$ & $1.58(1.35-1.84)$ & $2.00(1.67-2.39)$ & $<0.001$ \\
\hline PR difference ( $p$ value) & \multicolumn{4}{|c|}{$\left\llcorner p=0.028 \sqcup \quad\left\llcorner p=0.738 \_\quad L_{p=0.047}\right\lrcorner\right.$} & \\
\hline
\end{tabular}

\section{DISCUSSION}

Our findings revealed different patterns in employment inequalities according to occupational positions (professional vs. nonprofessional) and gender during the period 1995-2006. Among the professional group, absolute employment-related health inequalities steadily increased in both men $(2.6 \%$ increase) and women $(6.0 \%$ increase). Among the nonprofessional groups, significantly increasing relative health inequalities according to employment status were found among women in temporary and daily employment $(p$ for trend $=0.009,<0.001$, respectively) and among men in daily employment ( $p$ for trend $=0.001$ ).

Our results contradict previous findings from Western countries, which observed no health inequality between standard and fixed-term workers $[5,20]$. Differing socioeconomic, political, or cultural contexts between countries might result in contradictory findings. Thanks to an improved living standard alongside unprecedented economic growth, high educational achievement, and an increase in medical-care use in South Korea, the overall levels of poor self-rated health for employees ameliorated remarkably during the study period [21]. However, the improvement in employees' poor selfrated health was much more noticeable for permanent employees than for temporary or daily employees; this created widening gaps in absolute and relative employment health inequalities (especially among temporary workers in the professional position and daily workers in the nonprofessional position).

Our study revealed that professional employees were generally healthier than nonprofessional employees during the study period. Yet at the same time, the problem of absolute employment-related health inequalities increased, and relative health inequalities also seemed to be greater in both genders. Furthermore, the proportion of temporary employees, especially 
among female professional workers more so than among their male counterparts, increased alarmingly between 1995 and 2006 (a 13.3\%, a 4.4\% increase respectively). Although little literature exists on employment-related health inequalities in the professional position, this phenomenon could be explained by Korea's social and cultural contexts. Due to Confucian patriarchal beliefs, elite Korean women have traditionally valued family life more than a career. Unlike Western countries, Confucian societies, such as South Korea and Japan, continue to show an M-shaped curve pattern (a diagram of female labor-market participation rates by age) [22]. Recently, changes in family dynamics, an increase in the number of educated women, and rapid industrialization have motivated more married women to participate in the labor market [23]. Although our study showed that many elite Korean women have achieved high professional positions, from $26 \%$ in 1995 to $40.8 \%$ in 2006 , they, especially those who are married, might have to choose nonstandard work. Assuming that professional work requires lifelong job training, married women reentering the labor market tended to gravitate towards nonstandard work [24]. Additionally, the autonomy and high income of professional temporary employees was seemingly threatened following the 1997 Korean economic downturn. A further detailed analysis of the National Health and Nutrition Survey (1995-2005) supports this link; after the economic crisis, the healthy lifestyles of professional temporary employees, who in 1995 experienced less stress, more sleep, and more rest, worsened more than that of professional permanent employees (data not shown). A Korean report [16] showed that the health behaviors of male professional temporary employees were worsening, and apparently they worked longer hours than their permanent counterparts (51.5 versus 46.5 hours per a week); this is in line with a finding from a US study [9].

Interestingly, our study observed that, in 1995, female permanent employees in the professional group reported a greater prevalence of poor self-rated health than male permanent employees (11.6\% vs. 8.4\%), and this trend was reversed in 2006 (3.8\% vs. $4.0 \%$ ). This finding might have stumbled upon the higher stress of the workto-family conflict for female than for male permanent employees in a patriarchal society. Sekine et al (2006). argued that more women than men suffer from sleep deprivation, regardless of social class, and women's sleep deprivation could reflect the multiple roles that they must deal with-stress-filled roles which adversely impact their health [25]. However, the remarkable improvement in poor self-rated health among female professional permanent employees could highlight the transition of elite Korean women into favorable working conditions and stronger family supports that lead to more balance and less stress in their lives. A recent Korean study, in 2005, also suggested that the female nonmanual group enjoyed better health than female manual employees and housewives [23]. In contrast, these recently observed absolute and relative health disparities among elite male and female workers could reflect the aggravated working conditions for professional temporary employment. Thus effective monitoring for employment-related health inequality should be implemented for the professional group.

Among nonprofessional positions, approximately $70 \%$ of female employees and $40 \%$ of male employees fell into temporary or daily employment. Graded absolute and relative employment-related health inequalities remained virtually identical for both genders during the study period. However, the prevalence of poor self-rated health was much greater among female than male workers. The relative health inequalities have significantly increased among male and female workers, especially among daily workers $(p=0.001,<0.0001$, respectively). The trend test results also showed that relative employment-related health inequalities among female daily workers became more severe in 2006 than in 2003 ( $p=0.047)$. Some researchers argue that the high levels of detrimental health among female nonstandard employees might be caused by an excessive reporting bias; the gender paradox of the "myth of female excessive morbidity." Recently emerging empirical evidence from many developed countries showed a narrowing gap of health inequality between men and women [26,27]. Our study also showed a similar prevalence for poor self-rated health in professional male and female employees in 2006 (permenent: 4.1 vs. 4.0; temporary: 8.9 vs. 7.5). A significant amount of evidence has revealed that health inequalities according to employment status remain, even after controlling for socio-economic determinants [1-4]. The poorer health of female temporary and daily employees, thus, might reveal a causal link to structural discrimination in the workplace-occupational sex segregation, low control, high demand, few benefits, and low salaries [28,29]. Furthermore, limited resources, such as family and social supports for female nonstandard employees, might contribute to their poor self-rated health $[3,25]$. In particular, a lack of job security and insufficient salaries are more likely to contribute to the increase in relative health inequalities for female daily employees [1-3].

Not surprisingly, our study indicated that a remarkable 
growth in employment-related health inequalities occurred between 1995 and 1999, especially among male and female daily employees. Additionally, in 2006, these gaps of relative inequalities widened among women while they seemingly narrowed among men. The Korean economic downturn in 1997, which accompanied globalization and liberalization, could be a stimulating factor for the increase in employment-related health inequalities in the nonprofessional position since these workers can be laid-off more easily, thus making them vulnerable to adverse health effects. Even women who had obtained high educational levels and/or professional careers were likely to experience indiscriminate pressure from patriarchal social norms [30,31]. According to a recent Korean study on "economic crisis and working women [31]", companies in a massive reconstruction process have reduced employment costs by reassigning female employees from standard to nonstandard employment. Though managing the same workload, many women in nonstandard employment reportedly earned much less than they did previously in their standard positions [30,32].

The South Korean tripartite commission (government, labor unions, and management) in 1998 and the Ministry of Women's affairs in 2001 were established to protect nonstandard employees and implement gender-sensitive policy in the labor market $[33,34]$. The South Korean government has continuously enacted affirmative policies, such as expanding employment-insurance benefits, ratifying anti-discrimination legislation, and passing the Equal Employment Act $[35,36]$. However, the gender-sensitive policy to reduce employmentrelated discrimination was unlikely to be successful because the Korean government failed efficaciously to implement and monitor it [37]. Based on our trend test results, South Korean efforts are unlikely to contribute to the improvement of employment health inequalities. South Korea has failed to enhance this asymmetry in its social welfare network for temporary and daily workers [35-37]. For instance, in 2007, participation rate of unemployment-insurance program appeared to be strikingly lower among nonstandard than permanent employees (33\% versus $83.9 \%$ ) [35,38]. Therefore, in view of the high concentration of female nonstandard workers among women and the alarming increase in health inequalities between permanent and temporary or daily employment, special consideration to protect them from hazardous working environments should be given to these employees.

Although we can generalize our results, which used
South Korean representative samples, to the nationwide population, our study has two limitations. Firstly, it used poor self-rated health as a health indicator-an indicator that might not clearly expose objective measures of health, such as physical conditions or chronic diseases. Many recent studies, nevertheless, have suggested that self-rated health is considered not only to be a significant predictor of a variety of health conditions, such as chronic diseases, mental disorders, and mortality, but also to reflect dynamic social environments, such as social supports, social networks, or socio-psychological states [39]. Secondly, by using cross-sectional data, "healthy worker effect" might have skewed our findings. A previous review study argued that as the unemployment rate increases in a labor market, the tendency of employers is to draw healthy recruits, as nonstandard workers, out of the vast pool of the unemployed [6]. As a result, the real impact of employment health inequalities might provide misleading evidence for our research since, following the 1997 economic crisis, the unemployment rate was a record-high of $6.3 \%$, when compared to a record-low of $2 \%$ in 1996 [37]. A Korean study indicated that nonstandard employees held on to their jobs for more than 4 years and the turnover rate was $2.5 \%$. Considering the nonstandard work characteristics of the Korean market, this possibility of "healthy worker effect" was less likely to influence our results. The suspected causality of employment health inequalities, however, should be ascertained with further research.

Our findings suggest that tackling health determinants surrounding temporary and daily employees should become a central feature of the government's egalitarian policies for the labor market, regardless of gender and occupational position. What areas of policy ought to be considered: unemployment benefits, collective bargaining agreements, job training and placement, as well as gender equality.

\section{ACKNOWLEDGMENTS}

This research is supported by the Social Aetiology and Mental Illness program (SAMI). SAMI is a Strategic Training Initiative in Health Research funded by the Canadian Institutes of Health Research at the Centre for Addiction and Mental health and the University of Toronto. We also would like to thank Thomas W. Beechinor for his help and support. 


\section{REFERENCE}

1. Kim IH, Khang YH, Muntaner C, Chun H, Cho SI. Gender, precarious work, and chronic diseases in South Korea. Am J Ind Med 2008; 51(10): 748-757.

2. Kim IH, Muntaner C, Khang YH, Paek D, Cho SI. The relationship between nonstandard working and mental health in a representative sample of the South Korean population. Soc Sci Med 2006; 63(3): 566-574.

3. Kim IH, Paek DM, Cho SI. Does non-standard work affect health? J Prev Med Public Health 2005; 38(3): 337-344. (Korean)

4. Kim MH, Kim CY, Park JK, Kawachi I. Is precarious employment damaging to self-rated health? Results of propensity score matching methods, using longitudinal data in South Korea. Soc Sci Med 2008; 67(12): 1982-1994.

5. Artazcoz L, Benach J, Borrell C, Cortès I. Social inequalities in the impact of flexible employment on different domains of psychosocial health. J Epidemiol Community Health 2005; 59(9): 761-767.

6. Virtanen M, Kivimäki M, Joensuu M, Virtanen P, Elovainio M, Vahtera J. Temporary employment and health: a review. Int J Epidemiol 2005; 34(3): 610-622.

7. Freidson E. The changing nature of professional control. Annu Rev Sociol 1984;10: 1-20.

8. Hoque K, Kirkpatrick I. Non-standard employment in the management and professional workforce: training, consultation and gender implications. Work Employ Soc 2003; 17(4): 667-689.

9. Spalter-Roth RM, Kallegerg AL, Rasell E, Cassirer N, Reskin BF, Hudson K, et al. Managing work and family; nonstandard work arrangements among managers and professionals. Washington DC: Economic Policy Institute; 1997.

10. Rasell ME, Appelbaum E. The changing pattern of employment relations. New Dir Higher Educ 1998;104: 29-38.

11. Wilthagen T. Flexicurity: a new paradigm for labor market policy reform? Amsterdam: Hugo Sinzheimer Institute; 1998

12. Clasen J. Modern social democracy and european welfare state reform. Soc Policy Soc 2002; 1(1): 67-76.

13. You B, Kim C, Kim S. Labor market policies to meet challenges in the Korea labor market after the 1997 financial crisis. International conference on flexibility and performance: International perspective on labor market institutions. Seoul: Korea; 2004.

14. International Labour Office. Global employment trends 2004: the World Employment Reports. Geneva: International Labour Organization; 2004.

15. Ministry of Labor. Government report for protection law of nonstandard workers. Gwacheon: Ministry of Labor; 2004. (Korean)

16. Korean National Statistical Office. Korean statistical information system, statistical database. Daejeon: National
Statistical Office; 2008.(Korean)

17. International Labour Office. International standard classification of occupations: ISCO-88. Geneva: International Labour Office; 1990.

18. Khang YH, Yun SC, Lynch JW. Monitoring trends in socioeconomic health inequalities: it matters how you measure. BMC Public Health 2008; 8: 66.

19. Spiegelman D, Hertzmark E. Easy SAS calculations for risk or prevalence ratios and differences. Am J Epidemiol 2005; 162(3): 199-200.

20. Virtanen P, Saloniemi A, Vahtera J, Kivimaäki M, Virtanen M, Koskenvuo M. The working conditions and health of non-permanent employees: are there differences between private and public labour markets? Econ Ind Democracy 2006; 27(1): 39-65.

21. Preston SH. The changing relation between mortality and level of economic development. Int J Epidemiol 2007; 36(3): 484-490.

22. Brinton MC. Women's working lives in East Asia. Stanford, CA: Stanford University Press; 2001.

23. Kim IH, Chun H. Employment and married women's health in Korea: beneficial or harmful? J Prev Med Public Health 2009; 42(5): 323-330. (Korean)

24. Davenport ES, Fry H, Pee B, Woodman T. Learning throughout life: can a progress file help? Br Dent J 2003; 195(2): 101-105.

25. Sekine M, Chandola T, Martikainen P, Marmot M, Kagamimori S. Work and family characteristics as determinants of socioeconomic and sex inequalities in sleep: The Japanese Civil Servants Study. Sleep 2006; 29(2): 206-216.

26. Lahelma E, Arber S, Martikainen P, Rahkonen O, Silventoinen K. The myth of gender differences in health: social structural determinants across adult ages in Britain and Finland. Curr Sociol 2001; 49(3): 31-54.

27. Arber S, Cooper H. Gender differences in health in later life: the new paradox? Soc Sci Med 1999; 48(1): 61-76.

28. Chun H, Khang YH, Kim IH, Cho SI. Explaining gender differences in ill-health in South Korea: the roles of sociostructural, psychosocial, and behavioral factors. Soc Sci Med 2008; 67(6): 988-1001

29. Menéndez M, Benach J, Muntaner C, Amable M, O'Campo P. Is precarious employment more damaging to women's health than men's? Soc Sci Med 2007; 64(4): 776-781.

30. Han J, Chang J. History and life-course in transfer from non-standard work to standard work. The Koran labor economic association dissertation. Seoul: Korea Labor Institute; 2003.

31. Chang J. Economic crisis and working women Korean Labor Institute Research Report 2001-03. Seoul: Korean Labor Institute; 2001.

32. Gash V, McGinnity F. Fixed-term contracts- the new European inequality? Comparing men and women in West Germany and France. Socioecon Rev 2007; 5(3): 467-496. 
33. International Labour Office. Tripartite commissionrepublic of Korea. Geneva: International Labour Organization; 2004.

34. Ju JS. The changes in female non-standard employment arrangement after nonstandard protection law in 2007 analysis of economically active population survey by the statistical survey bureau. Seoul: Korean Women's Development Institute; 2008.

35. Kim IH, Muntaner C, Chung H, Benach J, EMCONET Network. Case studies on employment-related health inequalities in countries representing different types of labor markets. Int J Health Serv 2010; 40(2): 255-267.
36. Ku I. Social welfare reform since the 1997 economic crisis in Korea: achievement, limits, and future prospects. Asian Soc Work Policy Rev 2007; 1(1): 21-35.

37. Cho J, Kwon T, Ahn J. Half success, half failure in Korean Affirmative Action: an empirical evaluation on corporate progress. Women Stud Int Forum 2010; 33(3): 264-273.

38. Ministry of Labor. Labor union summary: yearbook of labor statistics. Gwacheon: Ministry of Labor; 2007.

39. Benyamini Y, Idler EL. Community studies reporting association between self-rated health and mortality: additional studies, 1995 to 1998. Res Aging 1999; 21(3): 392-401. 